\title{
RESEARCH
}

Open Access

\section{Efficacy of transmastoidal galvanic stimulation on recovery outcomes in patients with unilateral peripheral vestibular disorders: a randomized controlled trial}

Reham Ali Mohamed Ali Ahmed ${ }^{1 *}$, Ebtesam Mohamed Fahmy ${ }^{3}$, Amina Mohamed Awad $^{2}$, Mona Mohamed Hamdy ${ }^{3}$ and Hussein Ahmed Abd Rahman Shaker ${ }^{2}$

\begin{abstract}
Background: Peripheral vestibular disorders are common disorders among population with increased prevalence with age advancement, manifested by balance disorders and postural instability that negatively affect daily activities and social participation.

Objectives: To investigate the effect of transmastoidal galvanic stimulation added to a designed vestibular rehabilitation program on recovery outcomes in Egyptian patients with unilateral peripheral vestibular disorders.
\end{abstract}

Subjects and methods: Forty patients (from both sexes) diagnosed with unilateral peripheral vestibular weakness were evenly and randomly designated into two groups: study and control groups. The study group received transmastoidal galvanic stimulation, in addition to a vestibular rehabilitation program, whereas control group undergone vestibular rehabilitation program only. Treatment sessions were conducted three times weekly for four successive weeks. Assessment of vestibular canal weakness was carried out using videonystagmography, postural stability using computerized posturography, while participation in daily activities was carried out using Vestibular Disorders Activities of Daily Living Scale (VADL). All assessment measures were carried out pre- and post-treatment.

Results: Study group showed improvement of post-treatment scores of canal weakness, postural stability parameters, and VADL scale in reverse to control group that showed improvement of scores of preference and VADL only. A statistically significant difference was found between both groups in post-treatment scores of canal weakness, total equilibrium composite, and vestibular component with more improvement in the study group.

Conclusion: Adding transmastoidal galvanic stimulation to vestibular rehabilitation exercises for unilateral peripheral vestibular disorders improves the recovery outcomes of vestibular canal weakness, equilibrium, and vestibular components of postural stability.

(Continued on next page)

\footnotetext{
* Correspondence: rihamptagouza2008@gmail.com

'Department of Physical Therapy for Neuromuscular Disorders And Its Surgery, Faculty of Physical Therapy, Beni-Suef University, New Beni-Suef, Egypt

Full list of author information is available at the end of the article
}

(๑) The Author(s). 2020 Open Access This article is licensed under a Creative Commons Attribution 4.0 International License, which permits use, sharing, adaptation, distribution and reproduction in any medium or format, as long as you give appropriate credit to the original author(s) and the source, provide a link to the Creative Commons licence, and indicate if changes were made. The images or other third party material in this article are included in the article's Creative Commons licence, unless indicated otherwise in a credit line to the material. If material is not included in the article's Creative Commons licence and your intended use is not permitted by statutory regulation or exceeds the permitted use, you will need to obtain permission directly from the copyright holder. To view a copy of this licence, visit http://creativecommons.org/licenses/by/4.0/. 
(Continued from previous page)

Trial registration: Clinical trials identification number (NCT04010435). Registered 7 March 2019-retrospectively registered, https://register.clinicaltrials.gov/prs/app/action/LoginUser?ts=1\&cx=-jg9qo4

Keywords: Unilateral peripheral vestibular disorders, Transmastoidal galvanic stimulation, Vestibular rehabilitation, Recovery outcomes

\section{Introduction}

Vestibular dysfunctions can affect the overall quality of life for the affected patients. They are disabling disorders that can affect the patient's daily functions including social interactions/participation [1]. Despite the known disabling effects of vertigo, the exact impact on daily activities and social participation is not fully elucidated [2].

Unilateral peripheral vestibular disorders are defined as a disease or injury that affects the inner ear or higher centers that process the sensory information incorporated with controlling eye movements and postural balance. Unilateral weakness was defined as discrimination between the right and left side more than $25 \%$ in response to caloric testing $[3,4]$.

Activities of daily living (ADL) such as bathing, dressing, or moving around have been reported to be trivially restricted by chronic dizziness or imbalance, distressing $33.4 \%$ of adults with chronic imbalance and $11.5 \%$ of adults with chronic dizziness. The throbbing economic and social effects of dizziness are significantly underestimated [5].

Vestibular rehabilitation therapy (VRT) is an exercisebased treatment program used to improve vertigo, enhance gaze stability, provide postural stability, and improve participation in ADLs [6]. Vestibular rehabilitation exercises are typically based on motor learning principles. These exercises are subcategorized into: (i) adaptation exercises including visual/vestibular interaction and eye/hand coordination, implemented through repetitive and provocative movements of the head and/or eyes; (ii) habituation training using motion to habituate activity in vestibular nuclei; (iii) substitution which based on the use of single or combined sensory inputs to compensate for impaired vestibular input; (iv) postural control exercises, relaxation training, reconditioning activities, and functional/occupational retraining [7].

Transmastoidal galvanic stimulation has been identified to have a comprehended value to identify vestibular signal role in regulation of postural stability and balance during gait. This type of stimulation acts through booming the rate of firing of vestibular afferents by cathodal (negative) flow and diminishing vestibular afferents through anodal (positive) flow. Subsequently, asymmetrical tonic vestibular response is produced by the use of consistent bipolar galvanic current. This response causes standing subject to incline with different bearings according to current polarity and subject's head position [8].
Despite the proved effect of transmastoidal galvanic stimulation on postural stability in neurological disorders, there is a gap in the area of usage of transmastoidal galvanic stimulation as a treatment method for unilateral vestibular weakness and detecting its impact on postural stability components with implantation of videonystagmography findings as a method for detecting recovery in those patients. Accordingly, this study was conducted to investigate the effect of transmastoidal galvanic stimulation when added to a designed vestibular rehabilitation on recovery outcomes in Egyptian patients with unilateral peripheral vestibular disorder.

\section{Subjects and methods}

This is a prospective randomized, double-blinded, controlled clinical trial. The study was conducted between February 2019 and January 2020 following the Guidelines of Declaration of Helsinki on the conduct of human research. The study was approved by the institutional review board at the Faculty of Physical Therapy, Cairo University, with a reference number (No: P.T. REC/012/002202). It was registered on the website of clinical trials.gov with identification number (NCT04010435).

Sample size was determined prior to initiation of the study using G* power (version 3.1.9.2). Sample size calculation based on multivariate MNOVA: Global effect test, type I error (alpha $=0.05)$, and the effect size were obtained from the previous studies done on effect of transmastoidal electrical stimulation. Based on the data from these studies, it was estimated that a sample size of minimum 34 patients (17 patient in each group) would achieve a power of $95 \%$ (type II error) to detect effect size of 0.95 in the outcome measures of interest and after considering a $15 \%$ drop-out rate.

A convenient sample of 70 patients with chronic uncompensated unilateral peripheral vestibular weakness was screened for study eligibility (Fig. 1). Patients were enrolled from the Audiology and Balance Disturbances Out-patient Clinic, Faculty of Medicine, Cairo University. They were assessed for their eligibility to participate in the study; only forty subjects (of both genders) were enrolled. All patients were informed about the aim and procedures of the study with their right to withdraw whenever they want, and they signed consent form prior to participation. 


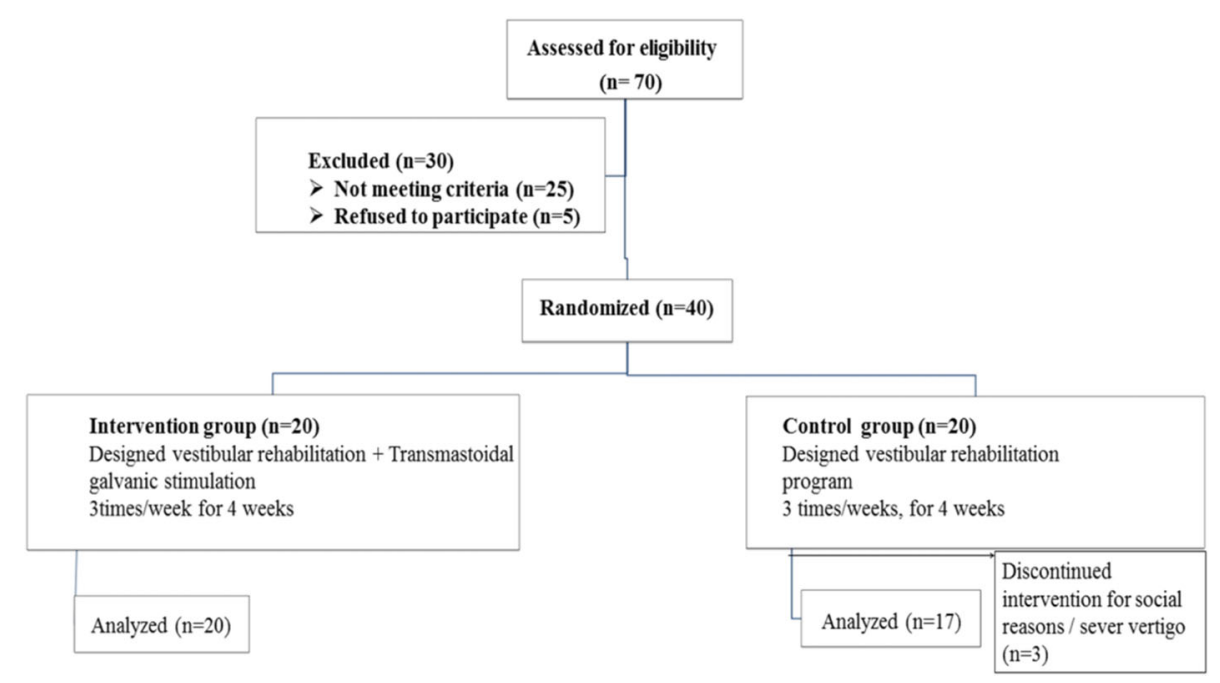

Fig. 1 Consort flow diagram. Seventy patients were assessed for eligibility to participate in the study. Thirty patients were excluded; twenty five patients were excluded as they do not fit inclusion criteria and five patients refused to participate. The remaining forty patients were randomized and equally divided into two groups, study group and control group. The study group included twenty patients who had completed the whole 4-week program and were involved in final analysis, whereas the control group included twenty patients, with three patients discontinued treatment sessions (15\% drop out), two patients for social reasons and one patient due to severe vertigo, with total number of patients that was analyzed seventeen patients. The total number of patients analyzed during this study was thirty seven patients.

Inclusion criteria were patients diagnosed by an audiologist as a chronic uncompensated unilateral peripheral vestibular weakness, age ranged from 30 to 60 years, and duration of illness ranged from 4 to 32 months.

Exclusion criteria were benign paroxysmal positional vertigo, bilateral peripheral vestibular weakness, central vestibular disorders, acute vestibular weakness, vertigo of vascular origin (Vertebro basilar insufficiency (VBI)) or cervical origin, and prior surgery of the ear. Patients with epilepsy, major psychiatric condition, unstable health conditions (cardiac dysfunction, end stage renal failure), patients with electrically implanted device, significant orthopedic problems, major cognitive dysfunction, chronic use of medications that influence motor or sensory excitability (antiepileptics or antipsychotic drugs), and alcohol abuse were also excluded $[9,10]$.

Patients were randomly divided into two groups, study group and control group, twenty patients in each group, by a blinded, independent research assistant who used random cards generated automatically by a computer (Fig. 1).

The study group received a transmastoidal galvanic vestibular stimulation, in addition to designed vestibular rehabilitation program (Vestibular exercises in the form of Cawthorne Cooksey exercises, gaze stabilization exercises, and postural control exercises) [8].

Transmastoidal galvanic vestibular stimulation was applied using a "phyaction 787-series made in holland" device. Transmastoidal GVS was applied from sitting position on a chair with a back support. The feet rested on the ground with $90^{\circ}$ flexed hips and knees. The inclination of the feet with respect to vertical line was around $30^{\circ}$, and the distance between them was $10 \mathrm{~cm}$ [11]. Trans-mastoid GVS was applied through two ECG adhesive electrodes $\left(3 \times 4 \mathrm{~cm}^{2}\right)$ after cleaning of the skin with alcohol. Bipolar orientation had been used; the anode had been placed on the mastoid process of healthy side while the cathode had been placed on the mastoid process of the affected side. The stimulation period lasted for 5 min in every setting with current intensity of about 4 milliampere (MA) and frequency of $0.5-1 \mathrm{~Hz}[12,13]$.

Cawthorne Cooksey exercises were carried in the following sequence: 1 st in bed exercises; eye movements (up and down, side to side, focusing on a finger that is one feet distance); head movements (bending up and down, side to side first with eye opened then closed). Second, sitting exercises involved same eye and head movements, shoulder shrugging, turning head and trunk alternately to the right and left, bending head and trunk forward, and pick an object from the ground. Third, standing exercises involved same eye, head, and shoulder movements, changing position from sitting to standing with eye open then closed, throw a ball from hand to hand above eye level, throw a ball from hand to hand beneath knee, changing position from sitting to standing and turn around in between. Fourth, moving around exercises where the patient revolved around a person sitting in the center who throw him a ball and to whom it was returned. Walk around room with eye open then closed, walk up and down a slope with eye open then closed, walk up and down stairs with eyes opened then closed and finally any activity 
involved throwing and catching a ball. All exercises were progressed from slow to fast rhythm. Depending on individualized severity of vertigo, patients displayed different rates of progression from the exercises done in bed to those on sitting or standing positions $[14,15]$.

Gaze stabilization exercises' aim was to enhance person's vision and ability to tract a fixed object while the head is moving. The rules of gaze stabilization exercises were based on previous studies. Patients performed exercise for gaze stability for $20 \mathrm{~min}$ [7].

Postural control exercises involved in this program included balance training from an upright standing position with different sensory input, changing body position, and walking training $[16,17]$.

The control group received the same designed vestibular rehabilitation program received by study group.

Patients performed $40 \mathrm{~min}$ for whole vestibular rehabilitation with time for rest in between exercises [18]. The vestibular rehabilitation exercises were applied for four successive weeks with a frequency of three sessions per week for 4 weeks $[19,20]$. The duration of session was 40 min for the control group and 45 min for the study group ( 5 min for galvanic stimulation +40 min for rehabilitation exercises).

Outcome measures are categorized into primary outcome measure, videonystagmography, and secondary outcome measures that included computerized dynamic posturography and vestibular disorders of daily living scale (VADL); both outcomes were implemented preand post-treatment by another assessor who was blinded about subject group allocation.

Videonystagmography (VNG) was used to assess unilateral vestibular canal weakness. It was used with caloric testing to analyze eye movements using video imaging technology, in which hi-tech video goggles with infrared cameras were used (Visual Eyes 2 channel for windows, version 8 release 1 (8.1.4)).

Computerized dynamic posturography was used to assess postural stability. Balance master (Version 8.0) (NeuroCom ${ }^{\circ}$ International, Inc., Clackamas, USA), sensory organization test (SOT) where six conditions were assimilated challenging components of sensory integration to maintain upright postural control [21]. The participants performed the six conditions of SOT and repeated each trial 3 times. Each trial lasted for $20 \mathrm{~s}$ in duration. Each person completed the testing in the standardized order as shown in Table 1.

A total equilibrium score was calculated to identify how much a participant can maintain his limits of stability in antro-posterior direction. The overall composite score was computed by integrating average score of each of six equilibrium conditions. Higher composite score reveals higher postural control. Interpretation of ratio scores of the somatosensory, visual, and vestibular systems conveys how much a participant is able to use those specific sensory cues for balance. The preference ratio defines how well a participant can ignore inaccurate visual clues in a situation of visual conflict [22], (Table 2).

Activities of daily living was assessed using Vestibular Disorders Activities of Daily living Scale (VADL) in which individuals rate their self-perceived disability level. The questionnaire includes 3 subscales: functional, ambulatory, and instrumental. The functional subscale evaluates individual's basic self-maintenance tasks; the ambulatory subscale evaluates perception of mobility related skills; and the instrumental subscale looks at selfperception in higher-level more socially complex tasks. Each item ranged from 1 (independent) to 10 (too difficult, no longer performed) [23].

The Arabic version of the VADL was used in the current study. This version is a valid one; in which forward and backward translation of the original scale was performed in the translation center at Cairo University. It was obtained from audiology and balance disturbances out-patient clinic, Faculty of Medicine, Cairo University.

\section{Statistical analysis}

All statistical analysis was performed using statistical package for the Social Sciences SPSS program version 20 for Windows (SPSS, Inc., Chicago, IL).Values were expressed as mean and standard deviation; prior to statistical analysis, data was tested for homogeneity and normality. Normality was tested using Shapiro-Wilk test, and outliers were identified by box and whisker plots.

Table 1 Sensory organization testing

\begin{tabular}{lllll}
\hline Test condition & Eyes & Surroundings & Platform & Sensory system used \\
\hline 1 & Open & Fixed & Fixed & Somatosensory \\
2 & Closed & NA & Fixed & Somatosensory \\
3 & Open & Sway referenced & Fixed & Somatosensory \\
4 & Open & Fixed & Sway referenced & Vision \\
5 & Closed & NA & Sway referenced & Vestibular \\
6 & Open & Sway referenced & Sway referenced & Vestibular \\
\hline
\end{tabular}

Adapted from Balance Manager Systems Clinical Interpretation Guide Computerized Dynamic Posturography, NeuroCom $N A$ not available 
Table 2 Sensory analysis interpretation

\begin{tabular}{ll}
\hline Ratio & Condition comparison \\
\hline Somatosensory (SOM) & 2 to 1 \\
Visual (Vis) & 4 to 1 \\
Vestibular (Vest) & 5 to 1 \\
Preference (Pref) & $(3+6)$ to $(2+5)$ \\
\hline
\end{tabular}

Adapted from Balance Manager Systems Clinical Interpretation Guide Computerized Dynamic Posturography, NeuroCom

Homogeneity of covariance was tested by Levene's test. With the presented findings of normal distribution of dependent parametric variables, the following statistical procedures were conducted: Descriptive statistical analysis and independent $t$ test was conducted for comparison of the subject characteristics between two groups and for clinical description of patients (age, weight, height, BMI, and duration of illness). $2 \times 2$ mixed multivariate analysis of variance (MANOVA) was used to compare the effect of treatment on mean values of canal weakness, total equilibrium composite, somatosensory (SOM), visual (Vis), vestibular (Vest), preference (Pref), and Vestibular Disorders Activities of Daily Living Scale. The level of significance for all statistical tests was set at $p<0.05$.

\section{Results}

General characteristics of participants of both groups are represented in Table 3.

\section{Within group analysis}

There was significant decrease in canal weakness mean scores post-treatment in the study group $(p<0.05)$ in reverse to the control group that shows no significant difference post-treatment $(p>0.05)$. Measurements of postural stability parameters showed significant increase of all mean scores post-treatment in the study group ( $p$ $<0.05)$, while in the control group, there was significant increase in the mean Pref scores post-treatment $(p<$ 0.05); however, total equilibrium composite, SOM, Vis, and Vest mean scores showed no significant difference between pre- and post-treatment values $(p>0.05)$.
VADL mean scores showed significant increase $(p<$ 0.05 ) in both groups post-treatment.

\section{Comparison between both groups}

Comparison between groups showed significant difference in post treatment mean scores of canal weakness, total equilibrium composite, and Vest between both groups with more improvement in the study group $(p<$ $0.05)$. However, there was no significant difference $(p>$ 0.05 ) in post-treatment mean values of SOM, Vis, Pref, and VADL between the two groups (Table 4).

\section{Discussion}

Unilateral peripheral vestibular dysfunctions are one of the most common causes of dizziness seen by health care professions, influencing dependency in self-care and mobility skills. To the best of our knowledge, no previous studies were conducted to investigate the impact of transmastoidal galvanic stimulation as a treatment method for unilateral vestibular weakness and detecting its impact on postural stability measured by computerized dynamic posturography. Also, implantation of videonystagmography findings as a method for detecting recovery outcome correlating it with outcomes of dynamic computerized posturography and participation in activities of daily living is considered as a new perspective we tried to cover in this study.

The current study showed significant improvement of canal paresis (weakness) in the study group posttreatment. This can be explained by the fact that bithermal caloric videonystagmography testing is usually an accustomed test assessing the horizontal canal function. Temperature fluctuations induce endolymph shifts causing hair cell activation. Traditional VNG testing evaluates only superior branch of the vestibular nerve and angular vestibulo-ocular reflex pathway. It does not test the functions of the utricle and saccule [24]. Regarding study group, galvanic vestibular stimulation has been found not only to stimulate otolith and semicircular canals afferents but also might influence vestibular hair cells $[25,26]$. GVS bypasses the hair cells and alters the firing rate of vestibular afferents that innervate underneath mastoids firing the

Table 3 General characteristics of participants

\begin{tabular}{|c|c|c|c|c|}
\hline \multirow[t]{2}{*}{ Items } & \multicolumn{2}{|c|}{ Groups (mean \pm SD) } & \multirow{2}{*}{$\begin{array}{l}t \\
\text { value }\end{array}$} & \multirow[t]{2}{*}{$p$ value } \\
\hline & Galvanic group & Control group & & \\
\hline Age (year) & $43.70 \pm 8.16$ & $42.82 \pm 6.87$ & 0.349 & 0.728 (NS) \\
\hline Weight (kg) & $75.55 \pm 10.11$ & $77.12 \pm 9.11$ & 0.491 & 0.626 (NS) \\
\hline Height (cm) & $163.45 \pm 6.27$ & $166.29 \pm 7.81$ & 1.228 & 0.227 (NS) \\
\hline BMI $\left(\mathrm{kg} / \mathrm{m}^{2}\right)$ & $28.27 \pm 3.36$ & $27.92 \pm 3.05$ & 0.178 & 0.860 (NS) \\
\hline Duration of illness (month) & $14.25 \pm 7.63$ & $15.35 \pm 6.59$ & 0.644 & 0.466 (NS) \\
\hline
\end{tabular}

Data are represented as $S D$ standard deviation, $B M I$ body mass index, $p$ value probability value

NS non-significant 
Table 4 Comparison of measured variables pre- and post-treatment within and between both groups

\begin{tabular}{|c|c|c|c|c|c|}
\hline \multirow[t]{2}{*}{ Variables } & & \multicolumn{2}{|c|}{ Groups (mean \pm SD) } & \multirow[t]{2}{*}{ F value } & \multirow[t]{2}{*}{$P$ value } \\
\hline & & Galvanic group & Control group & & \\
\hline \multirow[t]{6}{*}{ Canal weakness } & Pre-treatment & $57.75 \pm 20.21$ & $58.64 \pm 23.13$ & 0.016 & 0.901 (NS) \\
\hline & Post-treatment & $22.30 \pm 22.42$ & $45.00 \pm 23.61$ & 8.972 & $0.005(S)$ \\
\hline & Mean difference & 35.45 & 13.64 & & \\
\hline & Improvement \% & $61.39 \%$ & $23.26 \%$ & & \\
\hline & $F$ value & 27.578 & 2.897 & & \\
\hline & $P$ value & $0.0001(S)$ & 0.098 (NS) & & \\
\hline \multirow[t]{6}{*}{ Total equilibrium composite } & Pre-treatment & $39.60 \pm 11.16$ & $45.71 \pm 12.99$ & 2.365 & 0.133 (NS) \\
\hline & Post-treatment & $66.95 \pm 16.69$ & $49.12 \pm 13.98$ & 12.145 & $0.001(\mathrm{~S})$ \\
\hline & Mean difference & 27.35 & 3.41 & & \\
\hline & Improvement \% & $69.07 \%$ & $7.46 \%$ & & \\
\hline & $F$ value & 37.109 & 0.543 & & \\
\hline & $P$ value & $0.0001(S)$ & 0.467 (NS) & & \\
\hline \multirow[t]{6}{*}{ Somatosensory score } & Pre-treatment & $90.35 \pm 8.57$ & $91.76 \pm 9.35$ & 0.230 & 0.634 (NS) \\
\hline & Post-treatment & $95.65 \pm 5.30$ & $94.29 \pm 7.48$ & 0.413 & 0.524 (NS) \\
\hline & Mean difference & 5.30 & 2.53 & & \\
\hline & Improvement \% & $5.87 \%$ & $2.76 \%$ & & \\
\hline & $F$ value & 5.528 & 0.758 & & \\
\hline & $P$ value & $0.024(S)$ & 0.390 (NS) & & \\
\hline \multirow[t]{6}{*}{ Visual score } & Pre-treatment & $39.76 \pm 7.08$ & $41.77 \pm 26.29$ & 0.108 & 0.744 (NS) \\
\hline & Post-treatment & $55.75 \pm 21.20$ & $41.94 \pm 27.53$ & 2.966 & 0.094 (NS) \\
\hline & Mean difference & 15.99 & 0.17 & & \\
\hline & Improvement \% & $40.22 \%$ & $0.41 \%$ & & \\
\hline & $F$ value & 10.227 & 0.000 & & \\
\hline & $P$ value & $0.003(S)$ & 0.985 (NS) & & \\
\hline \multirow[t]{6}{*}{ Vestibular score } & Pre-treatment & $25.72 \pm 19.78$ & $19.47 \pm 19.48$ & 0.929 & 0.342 (NS) \\
\hline & Post-treatment & $45.75 \pm 25.46$ & $21.76 \pm 21.56$ & 9.364 & $0.004(S)$ \\
\hline & Mean difference & 20.03 & 2.29 & & \\
\hline & Improvement \% & $77.88 \%$ & $11.76 \%$ & & \\
\hline & $F$ value & 7.722 & 0.106 & & \\
\hline & $P$ value & $0.008(\mathrm{~S})$ & 0.747 (NS) & & \\
\hline \multirow[t]{6}{*}{ Preference score } & Pre-treatment & $76.60 \pm 8.25$ & $82.72 \pm 9.02$ & 3.207 & 0.082 (NS) \\
\hline & Post-treatment & $90.55 \pm 8.56$ & $94.56 \pm 7.96$ & 1.664 & 0.205 (NS) \\
\hline & Mean difference & 13.95 & 11.84 & & \\
\hline & Improvement \% & $18.21 \%$ & $14.31 \%$ & & \\
\hline & $F$ value & 27.513 & 9.131 & & \\
\hline & $P$ value & $0.0001(S)$ & $0.005(\mathrm{~S})$ & & \\
\hline \multirow[t]{6}{*}{ VADL score } & Pre-treatment & $101.75 \pm 29.42$ & $94.59 \pm 45.74$ & 0.330 & 0.569 (NS) \\
\hline & Post-treatment & $62.20 \pm 21.99$ & $67.18 \pm 37.08$ & 0.255 & 0.616 (NS) \\
\hline & Mean difference & 39.55 & 27.41 & & \\
\hline & Improvement \% & $38.87 \%$ & $28.98 \%$ & & \\
\hline & $F$ value & 23.182 & 6.684 & & \\
\hline & $P$ value & 0.0001 (S) & $0.024(\mathrm{~S})$ & & \\
\hline
\end{tabular}


brainstem nuclei and consistently activate the sensory system-associated cortical and subcortical regions $[16,27$, 28].

The present study disclosed improvement of canal weakness in the study group speculating that galvanic stimulation could enhance neurophysiological effects of vestibular rehabilitation exercises; these findings are incoherent with findings of Ricci and colleagues [29] who declared that VRT plays a major role in attaining vestibular compensation by means of central neuroplasticity mechanisms, with the target to temper or eradicate the vestibular manifestations. That can be physiologically explained by the fact that motion activates other sensory inputs (visual, proprioceptive, and somatosensory systems) [30].

Many studies had implied that after peripheral vestibular complications such as following labyrinthectomy, electrical stimulation can accelerate the compensatory process [31]. The vestibular symptoms that are elicited after unilateral peripheral lesions are recognized to an imbalance between resting discharge of either sides, and a decrease in signs and symptoms could also be achieved by CNS compensation. During CNS compensation, a decrease in nuclear activity in both medial vestibular nuclei occurs. This decrease in electrical activity is greater on the contralateral side than on the ipsilateral side. The ipsilateral nucleus undergoes a regeneration of its resting activity near the top of critical stage or the start of the acute stage [32].

Regarding postural stability, our study showed significant improvement in all measured parameters posttreatment in the study group, while in the control group, the scores of preference was improved post-treatment, but no significant difference was detected regarding posturography equilibrium composite, SOM, Vis and Vest scores post-treatment. These results agreed with Kataoka and colleagues [33] who reported enhancement of axial motor characteristic and postural instability of parkinsonian patients in response to transmastoidal galvanic stimulation. Also, Nooristani and colleagues [34] reported that postural balance following $30 \mathrm{~min}$ of nGVS led to a sustained post-stimulation improvement.

Further, Fujimoto and colleagues [35] examined the effects of lengthy-time period utility of $n$ GVS on static postural stability in benign positional vertigo patients and found that nGVS has a tremendous post-stimulation impact on postural stability especially on the rate of displacement of the center of pressure that lasts for several hours. In contradiction, Barozzi and colleagues [36] compared the outcomes of oculomotor rehabilitation on static balance and a dizziness handicap to the outcomes of vestibular electrical stimulation in twenty eight patients, using static posturography and the dizziness handicap inventory short form. They found no significant difference before and after treatment, revealing that both forms of therapy are effective.

Improvement of postural stability in the group that received galvanic stimulation can be explained through previous fMRI studies that had shown that GVS is liable to elicit activations within the fissure of Rolando, preand post-central gyri, middle, and inferior frontal gyri, supplementary motor region, cingulate cortex, inferior parietal lobule, insula and insular cortex and the cerebellum that has been implicated in vestibular perception $[28,37]$. In another fMRI study done by Fink and colleagues [38] investigating the galvanically induced effects on neural mechanisms underlying allocentric visuospatial adjustments in normal individuals, showing activation within the right ventral prefrontal and posterior parietal cortices.

In this study, it was observed that participants treated with galvanic stimulation presented with improved visual, vestibular, and somatosensory components of posturography after treatment, whereas patients dealt with vestibular rehabilitation physical activities showed improvement in the preference component only. These can be explained through Barozzi and colleagues [36] who reported that oculomotor training (gaze stabilization and Cawthorne Cooksey eye movements exercises) stimulating the proprioceptors of extraocular muscle probably provides somatosensory supplementary indicators that act on postural stability, while galvanic stimulation facilitates vestibular nuclei through the spino-vestibular pathways.

The results revealed by this study showed that the Values of Vestibular Disorders Activities of Daily Living Scale showed significant improvement post-treatment in both groups, with no significant difference between the two groups. This might suggest that the greater impact on participation in activities of daily living was mainly influenced by vestibular rehabilitation exercises. The improvement in the functional skills can be mostly attributed to decrease in the intensity of vertigo and improvement of postural stability as vestibular rehabilitation accelerates reimbursement and medication acts to suppress the labyrinthine. Since subjects felt better, shifting their head did no longer elicit vertigo, so they were better able to have interaction in self-care, mobility, home control, and vocational activities [39].

Cohen [40], conducted a study on twenty patients with chronic peripheral vestibular disorder randomly assigned into two groups, control group (only medication) and experimental group (vestibular habituation). Result showed that the total and all sub scores of VADL showed a very highly significant change in the experimental group following treatment, and they concluded that activities of daily living improved following vestibular rehabilitation as compared to medication only. Patatas and colleagues [41] 
also determined a tremendous improvement in the highquality of life (assessed with dizziness handicap inventory) after vestibular rehabilitation protocol, unbiased of age and gender.

Ganança and colleagues [42] reported that therapeutic exercises must be designed according to many considerations taking into account the individual's specific vestibular trouble, elimination of underlying disease, controlling of vertigo, vestibular neurophysiological compensations, and prevention of the irritating factors and the possible neurovegetative and psychoeffective symptoms. Despite the fact that there are numerous alternatives to relive or alleviate dizziness and its associated signs and symptoms, there is a growing inception that therapeutic motion is essential for patient's welfare, adopting the concept that this therapeutic motion must be properly tolerated by the patients with minimal side effects [42].

In a previous study by Aw and colleagues [43], forty patients were treated by combined galvanic vestibular stimulation and conventional vestibular rehabilitation showing a significant improvement compared to those on conventional vestibular rehabilitation alone. Those authors additionally performed sham stimulation on patients in the conventional vestibular rehabilitation group to eliminate any psychological improvement, which consolidate our results. Additionally, previous reports documented that galvanic vestibular stimulation is effective in unilateral vestibular pathologies [44] and enhanced vestibulo-ocular reflex in patients with sporadic episodes like Ménière's disease [45]. Although galvanic vestibular stimulation procedure and vestibular rehabilitation exercises are a non-invasive interventions that affect vestibular afferents similarly [43], however, GVS has both direct and indirect effects such as influencing posture, sway pattern of the body, and gait [10].

The current results suggest that a training program using GVS combined with selected physical therapy exercises improved objective measures of recovery outcomes in chronic unilateral vestibular disorders. This improvement occurred in a phase (after 3 months from onset) when significant recovery or functional gains are poorly expected. Furthermore, the improvement of recovery in the current study was not only seen in vestibular canal paresis or postural stability but also translated into clinically meaningful improvement in ADL activity and functions, and reduction of disability. It may be important to GVS to be combined with conventional programs. These findings set directions for future studies to overcome some of the limitations of the current study: firstly, the lack of follow-up for several months post rehabilitation program to evaluate the long lasting effect, secondly, certain secondary outcome variables such as selective evaluation of degree of dizziness and its correlation with degree of canal paresis and level of disability.
In the view of this study, adding on of galvanic vestibular stimulation to ordinary vestibular rehabilitation programs can have a clinical influence on overall recovery and regaining of the ability to participate more functionally at activities of daily living improving quality of life of patients suffering from unilateral peripheral vestibular disorders.

\section{Conclusion}

Adding transmastoidal galvanic stimulation to the designed vestibular rehabilitation program yielded significant improvement of canal paresis and some parameters of postural stability more than participation in activities of daily living.

\section{Abbreviations}

ADL: Activities of daily living; BMI: Body mass index; CNS: Central nervous system; ECG: Electrocardiogram; GVS: Galvanic vestibular stimulation; MA: Milliampere; nGVS: Noisy galvanic vestibular stimulation; Pref: Preference; SOM: Somatosensory; SOT: Sensory organization test; VADL: Vestibular Disorders Activities of Daily Living Scale; VBI: Vertebrobasilar insufficiency; Vest: Vestibular; Vis: Visual; VRT: Vestibular rehabilitation therapy

\section{Acknowledgements}

The authors would like to acknowledge all participants involved in this study.

\section{Authors' contributions}

"R A shared in the preparation of the research project, data collection, implantation of practical part, statistical analysis, interpretation of data, development of literature, preparation of the manuscript, and sent the manuscript for publication. E M shared in the preparation of the research project, data collection, neurological assessment, and statistical analysis. A M shared in the preparation of the research project and data collection. M M shared in preparation of the research project, audiological, and vestibular assessment. $\mathrm{H}$ A shared in the preparation of the research project, general supervision of the research project, and data collection." "All authors read and approved final manuscript."

\section{Funding}

No funding was obtained from any institution for our study.

\section{Availability of data and materials}

The datasets generated and/or analyzed during the current study are not publicly available due to current Cairo University regulations and Egyptian legislation but are available from the corresponding author on reasonable request and after institutional approval.

\section{Ethics approval and consent to participate}

The study was approved by the institutional review board at the Faculty of Physical Therapy, Cairo University, with a reference number (No: P.T. REC/ 012/002202). It was registered on the website of clinical trials.gov with identification number (NCT04010435). All patients were informed about aim, duration, and details of the procedures they will receive. They all signed an informed consent form before participation in the study with their right to withdraw whenever they want.

Consent for publication

"Not applicable"

\section{Competing interests}

The authors declare that they have no competing interests.

\section{Author details}

${ }^{1}$ Department of Physical Therapy for Neuromuscular Disorders And Its Surgery, Faculty of Physical Therapy, Beni-Suef University, New Beni-Suef, Egypt. ${ }^{2}$ Department of Physical Therapy for Neuromuscular Disorders And Its 
Surgery, Faculty of Physical Therapy, Cairo University, Giza, Egypt. ${ }^{3}$ Faculty of Medicine, Cairo University, Giza, Egypt.

Received: 28 April 2020 Accepted: 30 June 2020 Published online: 16 July 2020

\section{References}

1. Mueller M, Strobl R, Jahn K, Linkohr B, Ladwig KH, Mielck A, et al. Impact of vertigo and dizziness on self-perceived participation and autonomy in older adults- results from the KORA-Age study. Qual Life Res. 2014;23:2301-8.

2. Alghwiri AA, Marchetti GF, Whitney SL. Content comparison of self-report measures used in vestibular rehabilitation based on the international classification of functioning, disability and health. Phys Ther. 2011:91:346-57.

3. Agrawal Y, Carey JP, Della Santina CC, Schubert MC, Minor LB. Disorders of balance and vestibular function in US adults: data from the National Health and Nutrition Examination Survey, 2001-2004. Arch Intern Med. 2009;169: 938-44.

4. Jongkees LBW. Value of the caloric test of the labyrinth. Arch Otolaryngol. 1948:48:402-17.

5. Neuhauser HK, Radtke A, Von Brevern M, Lezius F, Feldmann M, Lempert T. Burden of dizziness and vertigo in the community. Arch Intern Med. 2008; 168:2118-24.

6. Tsukamoto HF, Costa Vde S, Silva RA Jr, Pelosi GG, Marchiori LL, Vaz CR, et al. Effectiveness of a vestibular rehabilitation protocol to improve the health-related quality of life and postural balance in patients with vertigo. Int Arch Otorhinolaryngol. 2015;19:238-47.

7. Han BI, Song HS, Kim JS. Vestibular rehabilitation therapy: review of indications, mechanisms, and key exercises. J Clin Neurol. 2011;7:184-96.

8. McDonnell MN, Hillier SL. Vestibular rehabilitation for unilateral peripheral vestibular dysfunction Cochrane Database Syst Rev; 2015.

9. Minor LB, Schessel DA, Carey JP. Ménière's disease. Curr Opin Neurol. 2004 17:9-16.

10. Karan A, Alptekin HK, Çapan N, Dıraçoğlu D, Saral I, Aydın S, et al. The efficacy of vestibular electrical stimulation on patients with unilateral vestibular pathologies. Turk J Phys Med Rehabil. 2017;63:149-54.

11. Quark G, Etard O, Normand H, Pottier M, Denise P. Low intensity galvanic vestibule-ocular reflex in normal subjects. Neurophysiol Clin. 1998;28:413-22.

12. MacDougall HG, Brizuela AE, Curthoys IS. Linearity, symmetry and additivity of the human eye- movement response to maintained unilateral and bilateral surface galvanic (DC) vestibular stimulation. Exp Brain Res. 2003;148: 166-75

13. Corna S, Nordone A, Prestinari A, Galante M. Comparison of CawthorneCooksey exercises and sinusoidal support surface translations to improve balance in patients with unilateral vestibular deficit. Arch Phys Med Rehabil. 2006;84:1173-84

14. Dix MR. Rehabilitation in vertigo. In: Dix MR, Hood JD, editors. Vertigo. New York: J Wiley \& Sons; 1984. p. 467-79.

15. Herdman SJ, Borello-France DF, Whitney SL. Treatment of vestibular hypofunction. In: Herdman SJ, editor. Vestibular rehabilitation. Philadelphia: FA Davis; 1994. p. 287-313.

16. Utz KS, Dimova V, Oppenländer K, Kerkhoff G. Electrified minds: transcranial direct current stimulation (tDCS) and galvanic vestibular stimulation (GVS) as methods of non-invasive brain stimulation in neuropsychology - a review of current data and future implications. Neuropsychologia. 2010;48:2789810.

17. Al-Azab IMAA, Elyazed TIA, Mohamed A. Transcranial magnetic stimulation versus electrical vestibular stimulation on balance in geriatrics parkinsonian patients. Int J Physiother Res. 2017;5:2464-70.

18. Herdman SJ, Hall CD, Schubert MC, Das VE, Tusa RJ. Recovery of dynamic visual acuity in bilateral vestibular hypofunction. Arch Otolaryngol Head Neck Surg. 2007;133:383-9.

19. Shepard NT, Telian SA. Programmatic vestibular rehabilitation. Otolaryngol Head Neck Surg. 1995;112:173-82.

20. Whitney SL, Rossi MM. Efficacy of vestibular rehabilitation. Orolaryngol Cli North Am. 2000;33:659-72.

21. Hebert JR, Manago MM. Reliability and validity of the computerized dynamic posturography sensory organization test in people with multiple sclerosis. Int J MS Care. 2017:19:151-7.

22. Pletcher ER, Williams VJ, Abt JP, Morgan PM, Parr JJ, Wohleber MF, Sell TC Normative data for the NeuroCom sensory organization test in US military special operations forces. J Athl Train. 2017;52:129-36.
23. Cohen HS. Use of the vestibular disorders activities of daily living scale to describe functional limitations in patients with vestibular disorders. J Vestib Res. 2014;24:33-8.

24. Bogle JM. Clinical evaluation of the vestibular nerve using vestibular evoked myogenic potentials. J Clin Neurophysiol. 2018;35:39-47.

25. Fitzpatrick RC, Day BL. Probing the human vestibular system with galvanic stimulation. J Appl Physiol. 2004;96:2301-16.

26. Bent LR, McFadyen BJ, Inglis JT. Visual-vestibular interactions in postural control during the execution of a dynamic task. Exp Brain Res. 2002;146: 490-500.

27. Stephan T, Deutschländer A, Nolte A, Schneider E, Wiesmann M, Brandt T, et al. Functional MRI of galvanic vestibular stimulation with alternating currents at different frequencies. Neuroimage. 2005;26:721-32.

28. Smith AT, Wall MB, Thilo KV. Vestibular inputs to human motion-sensitive visual cortex. Cereb Cortex. 2012;22:1068-77.

29. Ricci NA, Aratani MC, Doná F, Macedo C, Caovilla HH, Ganança FFA. Systematic review about the effects of the vestibular rehabilitation in middle-age and older adults. Rev Bras Fis. 2010;14:361-71.

30. Cullen KE. Sensory signals during active versus passive movement. Curr Opin Neurobiol. 2004;14:698-706.

31. Kim HJ, Choi JY, Son EJ, Lee WS. Response to galvanic vestibular stimulation in patients with unilateral vestibular loss. Laryngoscope. 2006;116:62-6.

32. Lacour M, Helmchen C, Vidal PP. Vestibular compensation: the neurootologist's best friend. J Neurol. 2016;263:54-64.

33. Kataoka H, Okada Y, Kiriyama T, Kita Y, Nakamura J, Morioka S, et al. Can postural instability respond to galvanic vestibular stimulation in patients with Parkinson's disease? J Mov Disord. 2016;9:40-3.

34. Nooristani M, Maheu M, Houde MS, Bacon BA, Champoux F. Questioning the lasting effect of galvanic vestibular stimulation on postural control. PLoS One. 2019;14:11.

35. Fujimoto C, Egami N, Kawahara T, Uemura Y, Yamamoto Y, Yamasoba T, et al. Noisy galvanic vestibular stimulation sustainably improves posture in bilateral vestibulopathy. Front Neurol. 2018;9:900.

36. Barozzi S, Di Berardino F, Arisi E, Cesarani A. A comparison between oculomotor rehabilitation and vestibular electrical stimulation in unilateral peripheral vestibular deficit. Int Tinnitus J. 2006;12:45-9.

37. Della-Justina HM, Manczak T, Winkler AM, de Araújo DB, de Souza MA Amaro E, et al. Galvanic vestibular stimulator for fMRI studies. Rev Bras Eng Biomédica. 2014;30:70-82.

38. Fink GR, Marshall JC, Weiss PH, Stephan T, Grefkes C, Shah NJ, et al. Performing allocentric visuospatial judgments with induced distortion of the egocentric reference frame: an fMRI study with clinical implications. Neuroimage. 2003;20:1505-17.

39. Hall CD, Herdman SJ, Whitney SL, Cass SP, Clendaniel RA, Fife TD. Vestibular rehabilitation for peripheral vestibular hypofunction: an evidence-based clinical practice guideline: from the American physical therapy association neurology section. J Neurol Phys Ther. 2016;40:124-55.

40. Cohen $\mathrm{H}$. Vestibular rehabilitation improves daily life function. Am J Occup Ther. 1994:48:919-25.

41. Patatas $\mathrm{OH}$, Ganança CF, Ganança FF. Quality of life of individuals submitted to vestibular rehabilitation. Braz J Otorhinolaryngol. 2009;75:387-94.

42. Ganança MM, Caovilla HH, Munhoz MSL, Ganança CF, da Silva MLG, Serafini F. Optimizing the pharmacological component of integrated balance therapy. Braz J Otorhinolaryngol. 2007;73:12-8.

43. Aw ST, Aw GE, Todd MJ, Halmagyi GMJ. Enhanced vestibulo-ocular reflex to electrical vestibular stimulation in Meniere's disease. J Assoc Res Otolaryngol. 2013;14:49-59.

44. Carmona S, Ferrero A, Pianetti G, Escolá N, Arteaga MV, Frankel L. Galvanic vestibular stimulation improves the results of vestibular rehabilitation. Ann N Y Acad Sci. 2011;1233:E1-7.

45. Maire R, Van Melle G. Vestibulo-ocular reflex characteristics in patients with unilateral Ménière's disease. Otol Neurotol. 2008;29:693-8.

\section{Publisher's Note}

Springer Nature remains neutral with regard to jurisdictional claims in published maps and institutional affiliations. 